\title{
A PORTABLE ELECTRONIC 'CALLING DEVICE' AS AN AID TO 'WEANING' VENTILATOR-DEPENDENT TETRAPLEGIC PATIENTS FROM INTERMITTENT POSITIVE PRESSURE VENTILATION
}

\author{
By P. Burnett, Senior Electronics Technician and R. A. Sutton, F.R.C.S.Ed. \\ Regional Spinal Injuries Unit, Hexham General Hospital, Hexham, Northumberland
}

Abstract. An electronic calling device has been developed. It is easily portable and can be operated by the severely paralysed tetraplegic patient in order to attract attention. The patient can operate the sensor either during artificial ventilation or when breathing spontaneously via the tracheostomy tube at a stage prior to the insertion of a speaking tube.

Key words: Very high cervical cord lesion; Difficulty in communication; Electronic calling device.

\section{Indication for Development}

THE psychological difficulties encountered by very high-level tetraplegic patients when being weaned from intermittent positive pressure ventilation (IPPV) are well recognised (Burnham \& Werner, 1978). During the process of gaining confidence whilst learning to breathe without the ventilator, many patients feel acutely dependent upon the attendant member of the spinal injury unit staff. This feeling of total dependence is partly related to difficulty in communication. (The patient is usually immobilised on skull traction, his limbs are completely paralysed and at this stage it may not be felt appropriate to fit a speaking tracheostomy tube.)

\section{Description of Electronic Calling Device (ECD)}

The device consists of an electronic module which is enclosed in a plastic container (Fig. I). The container is of the following dimensions, $10 \mathrm{~cm} \times 5 \mathrm{~cm} \times 4 \mathrm{~cm}$. It can be placed in any convenient position near to the patient's head. The sensor (Fig. 2) is supported from the container by a universally adjustable wire. Two additional fine wires provide an electrical circuit between the sensor and the electronic module.

\section{Operation of Device}

The container is placed beside the patient's head and the sensor is adjusted to lie within about $10 \mathrm{~cm}$ of the patient's mouth. In order to operate the caller the patient traps air in his mouth and blows over the sensor. The mouth is used as an air pump independently of the lungs. Alternatively, the patient can operate the device by touching the sensor with his tongue provided that the sensor is appropriately near. The calling device, when stimulated, emits a high-pitched whistle which is sustained for a few seconds and then dies away. The duration of the signal is proportional to the amount of moisture deposited on the sensor and can be controlled by the patient. 


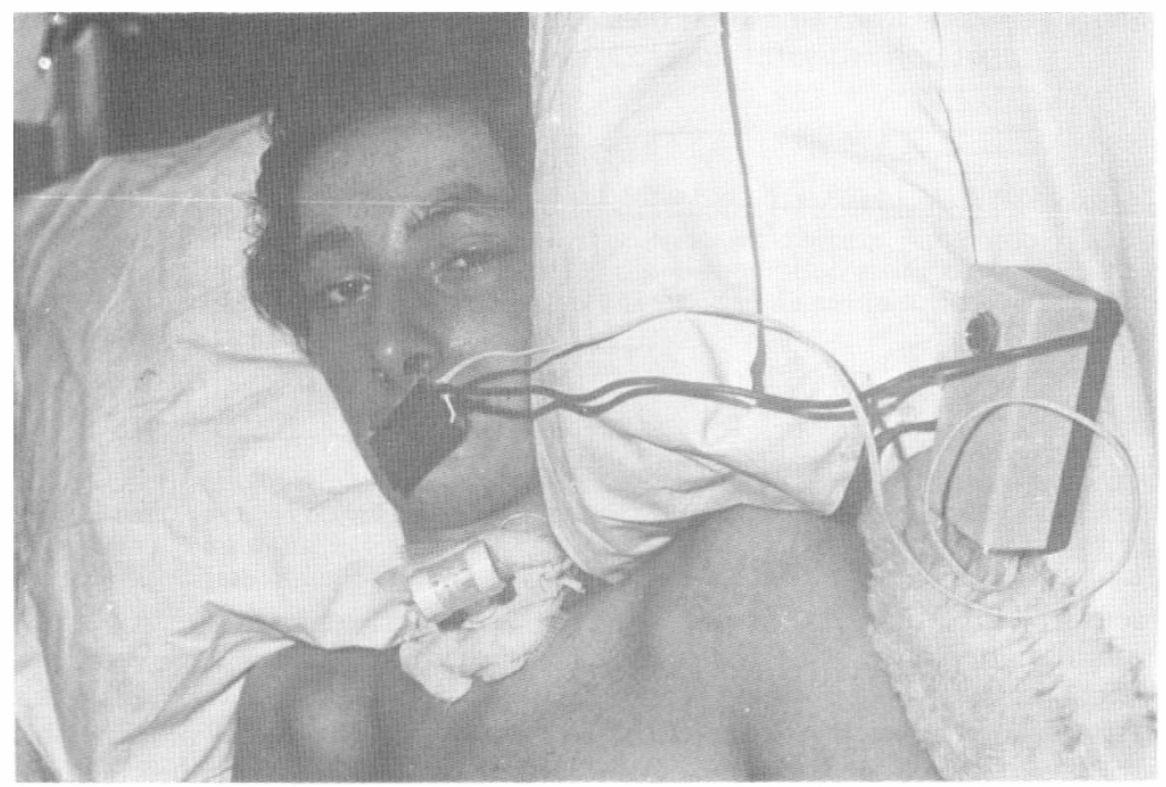

FIG. I

The electronic calling device.

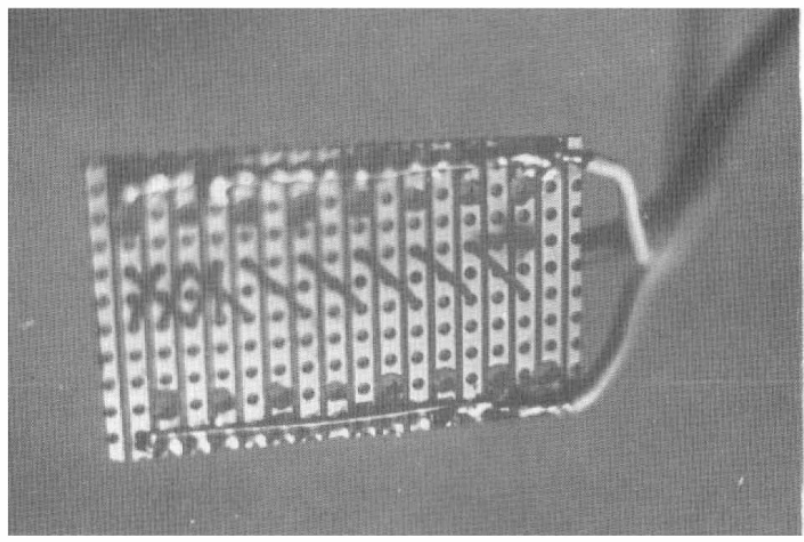

FIG. 2

The sensor.

\section{Technical Description}

(a) Circuit diagram (Fig. 3).

(b) Circuit function.

The sensor is constructed from a I-inch square of veroboard (approx. Io copper strips). Strips I, 3, 5, 7 and 9 are linked together and connected to battery positive. Strips 2, 4, 6, 8 and io are linked together and connected to the base of $\mathrm{T}_{1}$ (Fig. 3).

In the warm dry atmosphere of the ward or home no current will flow through I $7 / 4-E$ 


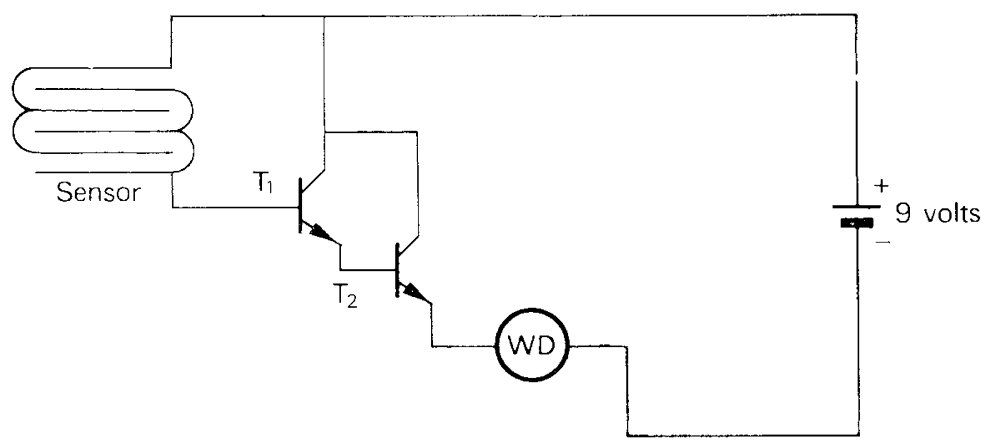

FIG. 3

Circuit diagram.

the sensor. Breathing on, or touching the sensor triggers $T_{1}$ and $T_{2}$ into conduction and the warning device, which requires Io milliamps at 9 volts for full output, sounds.

After about Io seconds (depending on the initial amount of moisture on the sensor) the moisture on the sensor evaporates and the alarm switches off.

The idling current of the device is typically less than I microamp and therefore no on/off switch is required. Battery life is up to I year depending on use.

\section{Components (Fig. 3)}

$\mathrm{T}_{1} \mathrm{~T}_{2}$ transistors B.C. 109 . . . . . . . . $£ 0.20 \mathrm{each}$

WD RS components warning device $\quad . \quad . \quad . \quad . \quad . \quad f_{3} 34$

Sensor I-inch square veroboard

Battery $\mathrm{PP}_{3}$

Box RS components 509-292 • . . . . . . $\quad$ I $1 \cdot 98$

\section{Case History}

A I 5-year-old schoolboy sustained a fracture dislocation at $\mathrm{C}_{3} / 4$ on the rugby field. He required mouth-to-mouth respiration on the field and tracheostomy was carried out on admission to his local hospital. He was transferred to the Spinal Injury Unit on IPPV. Open reduction of the spinal fracture proved necessary. Initially his periods of independent respiration were short and exhausting for him. Supervision was then too close to require any calling system. Gradually, over the following 6 weeks he was able to extend his time off IPPV until he was able to breathe adequately for I3 hours continuously. Throughout this latter period he felt secure in the knowledge that he could actively summon the immediate attention of his attendant nurse by using the ECD. He particularly felt more relaxed during the time when his attendant nurse changed shifts and had to pass on information to the arriving nurse.

\section{Discussion}

The ECD does not of course reduce the need for constant supervision by a highly trained nurse. We have found it, however, of great psychological value to the patient. Until it is felt appropriate to fit a speaking valve to the tracheostomy tube, the ECD is a useful aid to weaning tetraplegic patients from IPPV. The device is portable, reliable and is not expensive. If a speaking tube is not in use, 
the device is again valued by the patient when he begins to deliberately attempt to fall asleep without IPPV on the first few occasions after the accident.

\section{RÉSUMÉ}

Un dispositif d'appel électronique a été developpé. Il est facilement transportable et le tetraplegique gravement paralysé peut l'utiliser afin d'attirer l'attention. Le malade peut faire fonctionner le dispositif soit au cours d'une respiration artificielle, soit en respirant naturellement par le tube de trachéostomie à une période de temps antérieure à l'introduction d'un tube respiratoire.

\section{ZUSAMMENFASSUNG}

Eine electronische Rufanlage ist entwickelt worden. Sie ist leicht transportierbar und kann von dem durch Tetraplegie völlig gelähmten patienten bedient werden, um Aufmerksamkeit auf sich zu henken. Der Patient kann den Sensor betätigen, während er spontan durch eine Trachealkanüle atmet oder während er künstlich beatmet wird, bevor er fähig ist, $\mathrm{zu}$ sprechen.

\section{REFERENCES}

BURnhAM, L. \& Werner, G. (I978). The high level tetraplegic psychological survival and adjustment. Paraplegia, 16, I84-192. 